\title{
Contribuições de uma aula de campo para a aprendizagem de conhecimentos científicos nos anos iniciais do ensino fundamental
}

Contributions of a field class to the learning of scientific knowledge in the initial years of elementary education

\author{
Daniele Gaspari Fernandes ${ }^{1}$ \\ João Rodrigues Miguel ${ }^{2}$
}

\section{Resumo}

O ensino de ciências deve contribuir para a tomada de decisões, para uma compreensão mais ampla dos fenômenos da natureza e de como utilizar seus recursos. Neste trabalho são analisadas as contribuições de uma aula de ciências desenvolvida em ambiente natural para a aprendizagem de conteúdos científicos. A pesquisa foi realizada com uma turma do segundo ano do Ensino Fundamental da Escola Municipal Barão da Taquara, localizada em Duque de Caxias, na Baixada Fluminense - RJ. A coleta de dados teve como estratégias a confecção de desenhos antes e após a aula de campo, bem como a partir das falas dos estudantes sobre suas produções. Os resultados sugerem que essa metodologia contribuiu de forma significativa para a aprendizagem dos conteúdos, pois apresenta os conhecimentos de forma menos fragmentada; produz motivação e estímulo; proporciona situações de investigação e possibilita o ensino de forma concreta. A aula de campo ainda favorece uma postura de conservação do meio ambiente através da promoção de experiências que dificilmente podem ser recriadas no ambiente formal de educação.

Palavras chave metodologia de ensino; unidade de conservação; aprendizagem significativa

\begin{abstract}
The Science education should contribute to decision-making, a broader understanding of the phenomena of nature and the use of their resources. This work analyzes the contributions of a science class developed in natural environment for the learning of scientific contents. The survey was conducted with a group of second year of primary school from Barão da Taquara City Run School, which is located in Duque de Caxias, in The Baixada Fluminense - Rio de Janeiro - Brazil. The data collection process took as strategies making drawings before and after school, as well as from the students' experience speeches about their productions. The results suggest that this methodology contributed significantly to the content learning, because it offers the less fragmented knowledge, produces motivation and stimulation, provides research situations and allows the concrete teaching. In addition, the outdoor classes fosters an environmental conservation posture by promoting experiences that can hardly be recreated in formal education environment.

Keywords: teaching methodology; conservation unit; meaningful learning
\end{abstract}




\section{Introdução}

Os Parâmetros Curriculares Nacionais propõem um saber científico que contemple o constante aumento das informações científicas e tecnológicas, visando a uma formação crítico-social do estudante. O ensino de ciências deve abranger a compreensão do mundo, o reconhecimento do homem como ser e como parte de um todo, o universo. Esses conhecimentos podem contribuir para essa formação, para uma compreensão mais ampla dos fenômenos da natureza e de como preservar seus recursos, para a compreensão das tecnologias e das implicações éticas que se referem a elas (BRASIL, 1997).

É cada vez mais comum a presença da ciência em nossa sociedade, ou seja, os saberes científicos fazem parte da nossa cultura. E seus conceitos estão, muitas vezes, incorporados à linguagem comum. No entanto, esses conceitos do cotidiano apresentam um significado diferente daqueles que se almeja que os alunos compreendam após as aulas de ciências (PAVÃO, 2010).

O ensino dessa disciplina nas séries iniciais do ensino fundamental é muito relevante, contudo, mesmo com a sua inserção nos currículos e nas propostas pedagógicas, muitas crianças constroem um conhecimento científico insuficiente para compreender o mundo que as cerca e agir criticamente em situações que se faça necessário (FILHO et al, 2011).

No ensino de ciências, o professor deve assumir o papel de mediador do conhecimento, por entender que seus alunos não aprendem a partir de conceitos prontos, mas sim com a investigação, ou seja, com a experimentação, a pesquisa, a interação com o outro, a diferença de conhecimentos entre os sujeitos envolvidos, a integração entre diferentes áreas do conhecimento, a formulação de perguntas e a busca por respostas (PAVÃO, 2010).

Entretanto, a investigação não se resume a atividades experimentais. Investigar não é experimentar somente. Está intimamente ligado a atitudes e a maneiras de examinar o mundo. De modo que se torna imprescindível o professor introduzir atividades investigativas em suas aulas e reconhecer a importância da criatividade, inventividade, proposição de hipóteses, análise de dados, argumentação e comunicação de ideias (LIMA e MAUÉS, 2006).

\section{A aula de campo como metodologia de ensino}

Para Gohn (2010), a educação não-formal está vinculada à educação cidadã e à democratização dos conhecimentos. Seu objetivo é a formação crítica dos cidadãos, ciente de seus direitos e deveres. A autora ainda afirma que:

É um processo sociopolítico, cultural e pedagógico de formação para a cidadania, entendendo o político como a formação do indivíduo para interagir com o outro em sociedade. Ela designa um conjunto de práticas socioculturais de aprendizagem e produção de saberes, que envolve organizações/instituições, atividades, meios e formas variadas, assim como uma multiplicidade de programas e projetos sociais (GOHN, 2010, p.33). 
As escolas adotam as saídas de campo como metodologia de ensino e as realizam de formas variadas. Essa prática envolve inúmeras possibilidades de aprendizagem e apresentam a realidade sob uma nova ótica, sendo importantes para a formação cidadã do aluno. Envolve algumas etapas como: escolha do local de forma adequada aos estudantes envolvidos, levantamento de gastos com transporte, estadia e alimentação e planejamentos das ações (MARANDINO et al, 2011).

As atividades de campo permitem o ensino de conteúdos conceituais, procedimentais e atitudinais (VIVEIRO e DINIZ, 2009). O estudante tem a oportunidade de se perceber parte integrante da natureza e não apenas um expectador ou usuário de seus recursos. E pode, a partir daí, construir um senso de preservação dos ambientes naturais (SERRANO, 2000).

A maioria dos professores considera importante o trabalho com aulas de campo, no entanto, poucos o realizam. As principais obstruções para a sua realização são: receio de possíveis acidentes, insegurança quanto aos conteúdos que podem ser abordados durante a execução, dificuldade de conseguir autorização da escola e dos pais, implicação nos horários com outros professores, problemas com transportes. Alguns problemas que, em geral, são solucionados quando a atividade é num ambiente próximo à escola (KRASILCHIK, 2011).

Todavia, é importante que exista uma inter-relação entre as aprendizagens formais e as não-formais, pois o conhecimento é construído em meio a complexas relações sociais que integram essas duas aprendizagens. Tal abordagem pode contribuir para uma visão do processo de ensino-aprendizagem além da sala de aula, de modo que ambos se complementem, sem que exista um método melhor ou pior que o outro (COLLEYet al, 2002).

\section{Metodologia}

Essa pesquisa foi realizada com os alunos da turma 202, do segundo ano do Ensino Fundamental da Escola Municipal Barão da Taquara, que fica no terceiro distrito de Duque de Caxias - RJ. Ao todo, foram 14 alunos, com idade entre 7 e 8 anos. O local escolhido foi uma Unidade de Conservação Ambiental, o Parque Natural Municipal da Taquara (PARNAMTA), situado no mesmo bairro. O local é rico em trilhas ecológicas que atravessam fragmentos de Mata Atlântica. Na escolha da trilha para a realização deste estudo, levou-se em consideração as características dos sujeitos envolvidos na pesquisa: crianças ainda em processo de alfabetização. Durante o percurso tinha-se como intenção que os participantes expressassem de fato suas opiniões. Ao realizar uma entrevista tradicionalmente usada com adultos, por exemplo, as crianças podem pensar que se trata de uma atividade escolar com respostas pré-determinadas e responder aquilo que acredita ser a resposta "correta" (TAMMIVAARA e ENRIGHT, 1986 apud CURTIN, 2000). Ao utilizar métodos que sejam mais sensíveis às competências ou interesses particulares das crianças, cria-se um ambiente para que elas se sintam mais à vontade com um investigador adulto. (PUNCH, 2002).

Num primeiro momento os alunos foram orientados para elaborar duas ilustrações onde, na primeira, deveria desenhar uma planta e na segunda, demonstrar através do desenho uma importância dos vegetais. Essa primeira etapa foi desenvolvida nas dependências da escola, num dia de aula, em um período de aproximadamente uma hora cedido pela professora da turma. Ao final, cada aluno explicou o que havia desenhado e os pesquisadores escreveram na ilustração a fala dos alunos. 
Três dias depois, foi desenvolvida a aula de campo no PARNAMTA, adotando uma trilha interpretativa. Nesta trilha realizou-se três paradas em pontos com potencial pedagógico, previamente selecionados pelos pesquisadores, onde os assuntos foram discutidos mediante as observações do meio, troca de informações, indagações e respostas. Os conteúdos propostos foram: as plantas, suas partes - funções - e importâncias (RAVEN, 2007; AMABIS e MARTHO, 2015).

$\mathrm{Na}$ trilha os alunos demonstraram interesse também por outros assuntos como: a presença de lixo, da água, de animais e das residências dentro da Unidade de Conservação. Assuntos que não estavam previstos no roteiro original, veio da curiosidade do público alvo, foram discutidos e comentados, levando-se em consideração que as atividadees realizadas em ambientes naturais despertam a curiosidade e se constituemem "um instrumento de superação da fragmentação dos conteúdos" (SENICIATO E CAVASSAN, 2008).

No terceiro dia após a aula de campo, de volta na sala de aula, foram coletados mais dois desenhos semelhantes aos primeiros, para comparação entre eles e para avaliar se a metodologia usada contribuiu para a aprendizagem dos conteúdos abordados. Na análise dos desenhos foram considerados tanto a produção gráfica como as verbalizações dos alunos sobre seus desenhos. É importante destacar que a identidade dos estudantes foi mantida em sigilo, pois, cada um foi identificado por uma letra.

\section{Resultados e discussão}

Primeiro foram analisados os desenhos iniciais e finais sobre como é uma planta, considerando como o aluno expressou sua ideia, que partes do vegetal ele retratou e quais elementos relacionados ao ambiente estão presentes.

Quanto aos desenhos feitos antes da aula de campo sobre como é uma planta, 60\% dos alunos retrataram árvores e $40 \%$ as flores. A flor é a parte da planta mais atrativa valorizada por sua beleza, cores e cheiros. Muitas famílias têm em suas casas vegetais que apresentam flores vistosas como forma de embelezar o ambiente. Isso parece ter influenciado o ponto de vista desse percentual dos alunos sobre as plantas. Afonso (2005) alega que as crianças frequentemente confundem o todo com a parte, ou seja, a planta com a flor. $25 \%$ dos alunos desenhou as flores em vasos, indicando a influência cotidiana em suas concepções científicas.

Entre os 60\% dos alunos que desenharam árvores, 11\% desenharam as flores como parte da árvore; 89\% retrataram a flor e a árvore separadas, indicando um possível equívoco conceitual: a flor não é uma parte da árvore. Pavão (2010) argumenta que, apesar do conhecimento científico estar cada vez mais presente em nossa sociedade, por vezes, esse conhecimento não é similar àquele desejado após uma aula de ciências.

Após a aula de campo, todos os alunos retrataram sua noção de planta por meio de árvores, demonstrando muitas características observadas na maioria das plantas do Parque. O desenho do aluno P apresenta um grande número de informações discutidas durante a aula de campo. É possível observar as raízes, o tronco (e os galhos), as folhas e os frutos. Apesar de não ter desenhado as flores, o aluno ilustrou o lençol freático, que ele chamou apenas de "água", e os sais minerais do solo (Figura 1). 


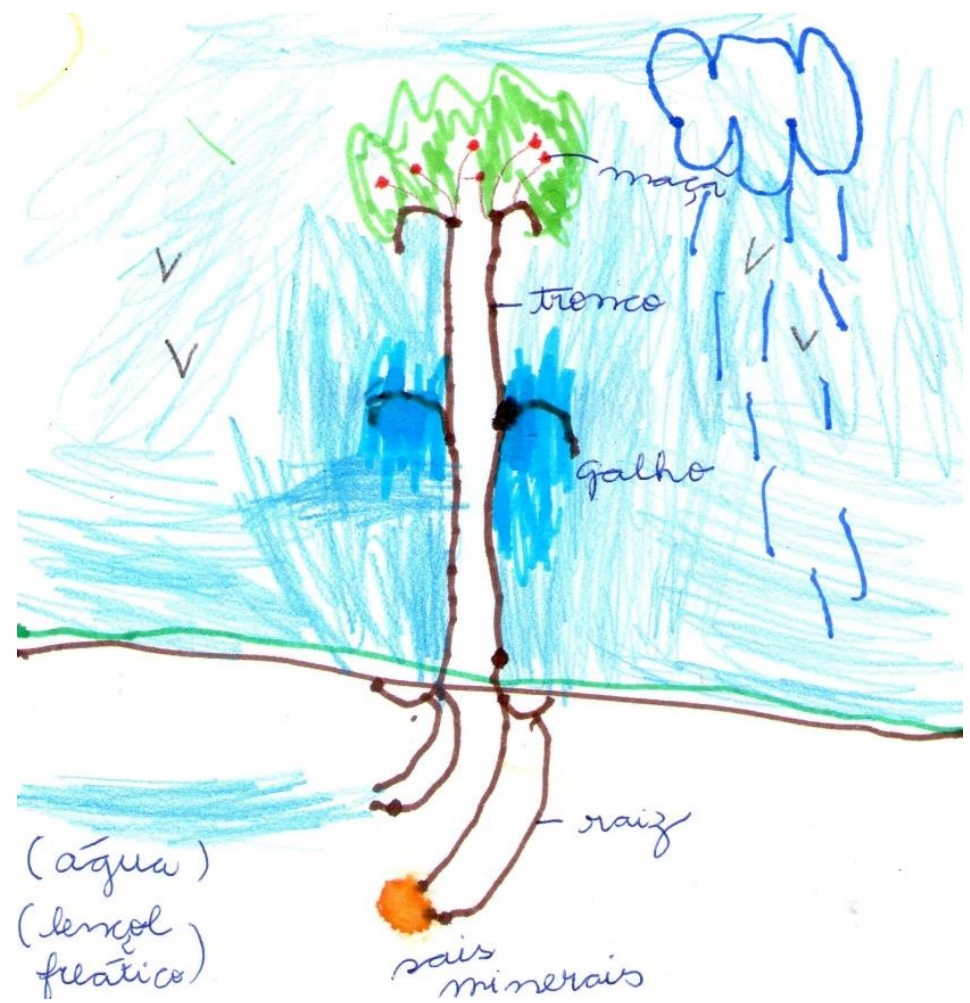

Figura 1 - Desenho final do aluno P.

Nesta segunda produção, 75\% dos alunos retrataram as flores. Dentre esses, 65\% desenharam as flores na árvore, indicando um aumento em relação à primeira ilustração. Observou-se que a aula de campo contribuiu para a aprendizagem de que as árvores apresentam flores, ou que a flor é parte integrante também das árvores.

Para verificar as mudanças ocorridas em relação ao conhecimento prévio e ao conhecimento adquirido após a aula de campo, passamos a interpretar o desenho inicial e final de alguns alunos, sujeitos da pesquisa. A figura 2 representa o desenho inicial e o final da aluna $P$.
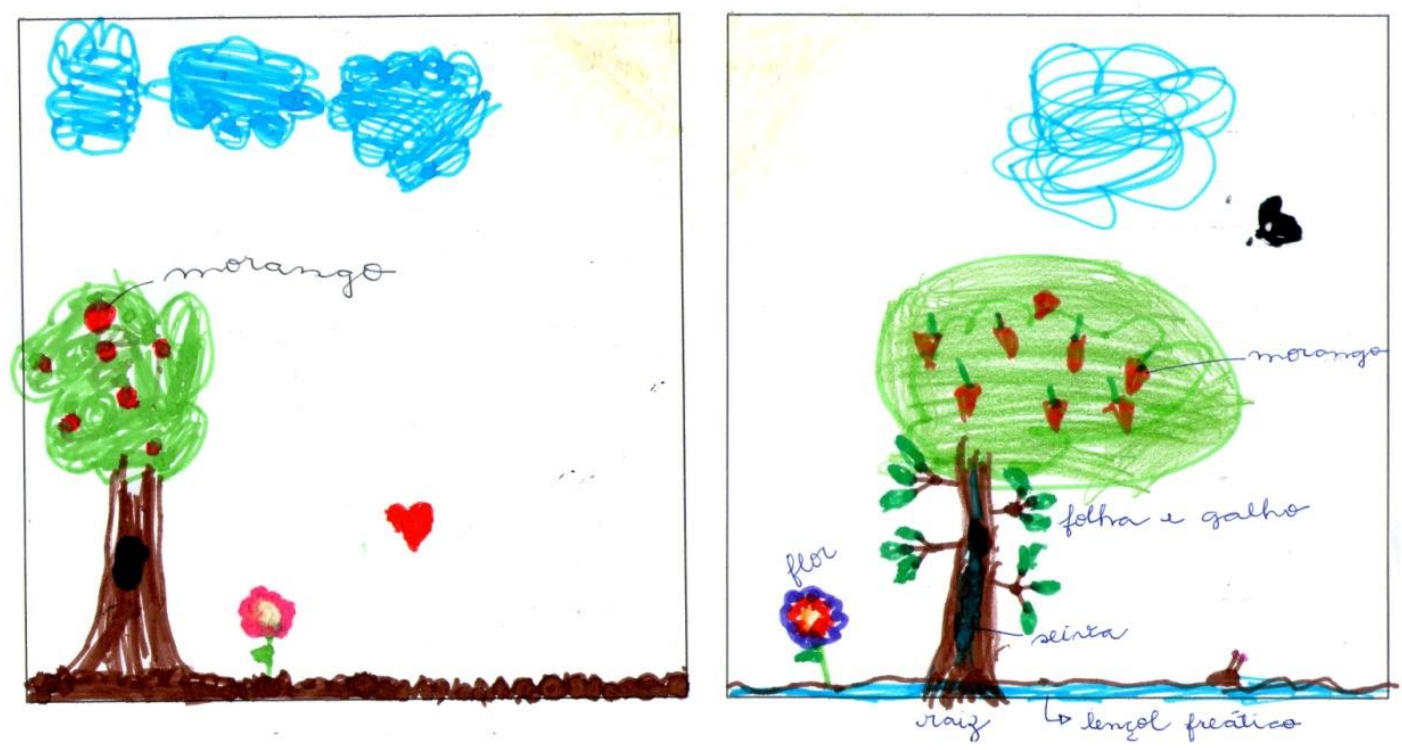

Figura 2 - Desenho inicial e final da aluna P. 
Na primeira produção é possível perceber o tronco, as folhas e os frutos (morangos). A flor e árvore estão separadas, indicando um possível equívoco quanto à flor não integrar a árvore. A aluna também retrata o meio onde esse vegetal está inserido ao desenhar o solo e as nuvens, indicando um conhecimento prévio do habitat natural das plantas.

Entretanto, na sua segunda produção aparecem novos elementos, ligados à experiência da aula de campo: a árvore agora apresenta galhos com folhas abaixo da copa, que é uma característica das árvores presentes no Parque; a raiz abaixo do solo; o lençol freático, que a aluna chamou de "água em baixo da terra", em referência à necessidade da planta de obter água através da raiz. O desenho ainda retrata a seiva, que a aluna chama de "água", possivelmente em alusão à seiva que escorria de uma das árvores durante a visita. Apesar de ainda desenhar a flor separada da árvore, o desenho final da aluna possui uma representação mais completa e complexa, levando em consideração o contexto observado durante a aula de campo.

A figura 3 reproduz os desenhos da aluna $K$, sendo inicial e final respectivamente.
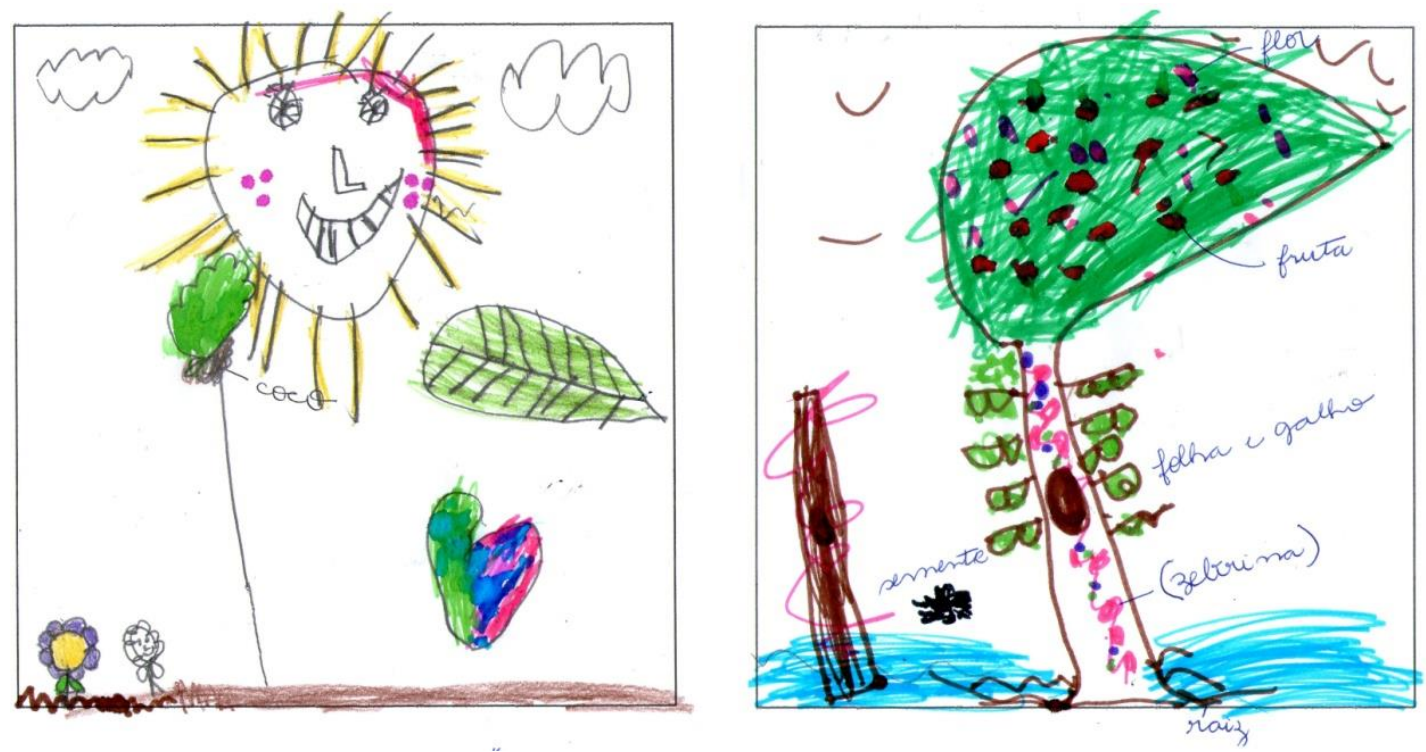

Figura 3 - Desenho inicial e final da aluna K.

Inicialmente, a aluna $\mathrm{K}$ retrata um coqueiro com seus respectivos frutos (coco). A aluna demonstra conhecer essa árvore, pois consegue expressar algumas de suas características: a altura, o caule ligeiramente mais fino e a localização dos frutos, abaixo das folhas. Assim como a primeira aluna, ela desenha a flor separada da árvore. Também retrata elementos do meio ambiente como o sol, as nuvens, o solo e um ser humano. Em seu desenho, a aluna ilustra uma folha isolada e de tamanho desproporcional em relação aos demais desenhos. Como a aluna já retratou as folhas no coqueiro, não acreditamos que ela pense que as mesmas não são parte das árvores. Consideramos que possivelmente ela tenha visto outros colegas desenhando as folhas dessa forma e quis acrescentar ao seu desenho. Também é plausível considerar que ao tentar retratar uma planta, ela tenha pensado nessa imagem da folha, já que a mesma é bem característica, entretanto, não a desenhou no coqueiro por que este já tinha sua própria folhagem.

Em seu desenho final podemos perceber um acréscimo considerável de informações advindas da aula de campo. A ilustração retrata uma árvore com as mesmas características encontradas no PARNAMTA: árvore alta, raízes aéreas, galhos com folhas abaixo do dossel, 
o rio, que corre bem próximo a algumas árvores e uma árvore seca observada durante a visita, que nos possibilitou discutir se as árvores morrem ou não - questão levantada pelos alunos. A aluna também desenhou as flores - dessa vez na árvore, os frutos e uma semente caindo no rio. Ainda ilustra a Tradescantia zebrina, popularmente conhecida como zebrina, planta herbácea suculenta e amplamente encontrada em regiões de Mata Atlântica (LORENZI e SOUZA, 2008). Essa espécie foi observada durante a aula vivendo tanto no solo quanto nos troncos das árvores. Nessa oportunidade, discutimos que uma das importâncias vegetais é servir de moradia (habitat) para outros seres vivos - vegetais, animais, fungos, líquens.

A partir dos desenhos da aluna $\mathrm{K}$ acreditamos que a aula de campo contribuiu para a aprendizagem de conteúdos científicos, pois retratam aspectos e situações que dificilmente seriam recriadas na sala de aula, além do mais, ao observar diretamente a natureza, os conteúdos se tornam menos fragmentados e englobam conhecimentos de várias áreas (VIEIRA et al, 2005).

A figura 4 retrata os desenhos do aluno $S$.

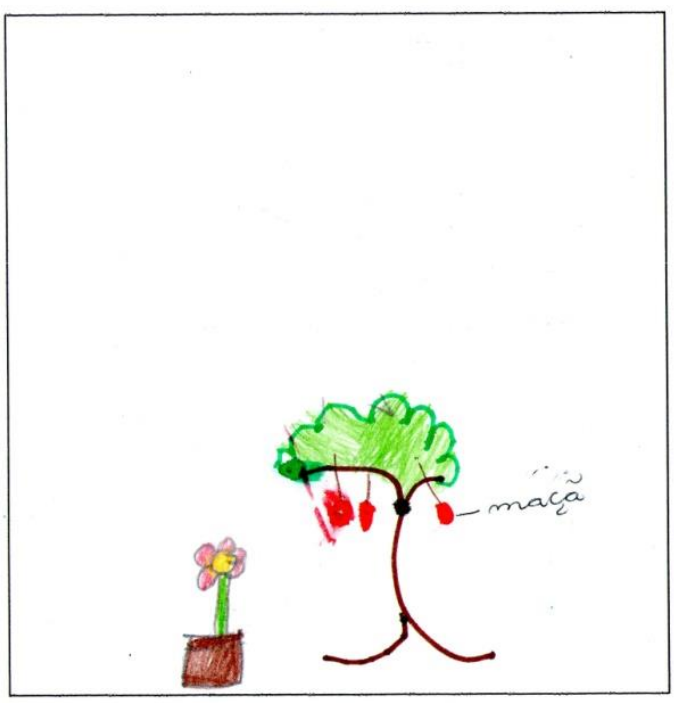

Figura 4 - Desenho inicial e final do aluno $\mathrm{S}$.

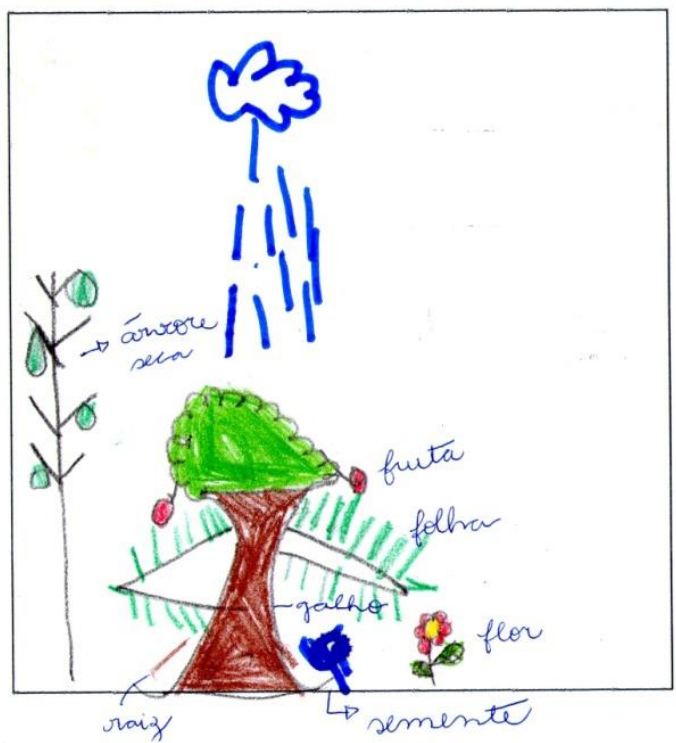

Em sua produção inicial, S expressa sua concepção de planta por meio de uma árvore em que se observa o tronco, as folhas e os frutos - que o próprio identificou como maçãs. A flor aparece, assim como nos desenhos de outros alunos, separada da árvore e plantada em vaso.

Sua produção final é mais complexa e retrata elementos presentes no meio natural. $\bigcirc$ aluno desenha uma árvore com galhos e folhas abaixo do dossel, raiz aérea, semente e frutos. A flor, agora planta no solo, ainda se encontra separada da árvore, indicando que ainda são necessários outros recursos para a aprendizagem de que esta estrutura também integra a árvore. $O$ aluno ainda ilustra outra árvore seca, em referência a uma árvore em processo de decomposição que observamos durante a aula.

É possível notar que muitos elementos presentes nos desenhos, tanto de $\mathrm{S}$ quanto dos outros alunos, estão relacionadosà saída de campo, visto que retratam situações muito peculiares à aula. Os desenhos que ilustram as sementes exemplificam bem isso, uma vez que elas não aparecem nos desenhos iniciais. No entanto, durante a aula, um dos alunos 
encontrou uma semente no chão e a partir deste fato, discutimos a importância e a função delas para os vegetais. Já na segunda produção, vários alunos desenharama semente como parte integrante das plantas e muitos a retratam no chão, possivelmente em referência ao local onde foi encontrada ou para ressaltar a função delas de germinação no solo.

A figura 5 corresponde aos desenhos da aluna $C$.
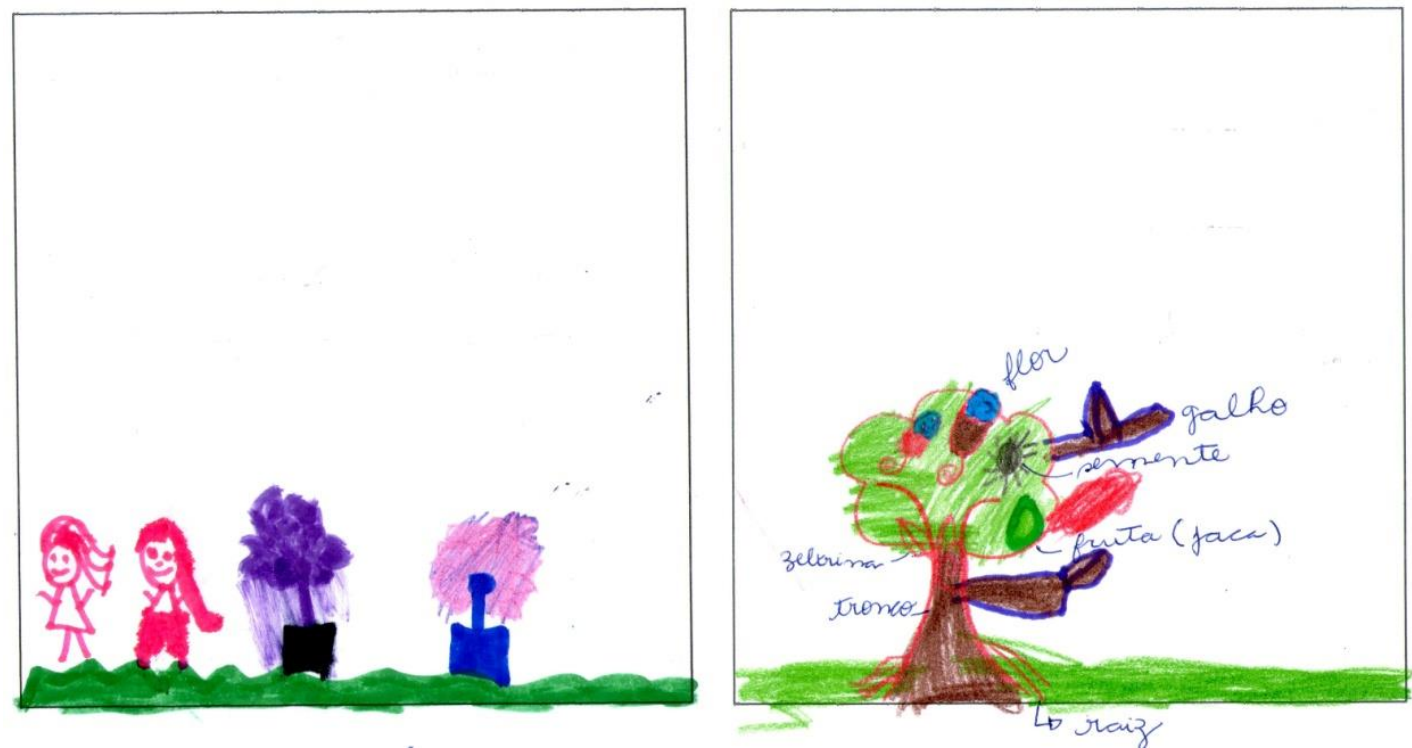

Figura 5 - Desenho inicial e final da aluna C

Em seu primeiro desenho, a aluna retrata duas flores. Apesar de desenhar o solo, essas plantas aparecem em vasos. Só é possível identificar a flor e o caule que a sustenta. Para integrar o ambiente, $\mathrm{C}$ desenha duas pessoas. Os elementos de seu desenho nos levaram a acreditar que a aluna retratou um ambiente não natural.

Ao analisar a segunda produção, observamos um aumento expressivo de informações sobre as plantas. A aluna desenha uma árvore completa, com raízes aéreas - que são abundantes no local visitado, tronco (galhos), folhas, flores, frutos e semente. Ao comentar seu desenho para os pesquisadores, a aluna fez questão de identificar o fruto como jaca, possivelmente em referência ao fruto da jaqueira encontrado durante a aula. Ao contrário de outros alunos, C desenha a semente ainda na copa da árvore e não no chão. Com essa observação fica evidente a evolução no aprendizado, já que a aluna identifica a semente como parte integrante da planta. A estudante ainda desenha a Tradescantia zebrina (zebrina), espécie vegetal que habita o tronco de árvores, comumente avistada durante a aula e já relatada nessa pesquisa.

Pela análise das imagens que foram expostas até o momento, entendemos que a visita ao espaço não formal de aprendizagem contribuiu de forma significativa para a construção de conhecimentos científicos sobre como é um vegetal e de quais partes é formado. Os resultados demonstram que a aula de campo é uma metodologia que contribui para a aprendizagem de conteúdos científicos nos anos iniciais do Ensino Fundamental, uma vez que, "favorecem (...) uma abordagem ao mesmo tempo mais complexa e menos abstrata dos fenômenos estudados" (SENICIATO e CAVASSAN, 2004).

Iremos analisar também os desenhos iniciais e finais dos alunos sobre a importância dos vegetais. Vale ressaltar que cada estudante explicou seu desenho e os pesquisadores 
registraram sua fala, que junto com as ilustrações, será usada para interpretar as concepções dos discentes.

Quanto aos desenhos feitos antes da aula de campo, 78,5\% dos alunos, ao expressarem seu ponto de vista sobre a relevância vegetal, retrataram as plantas embelezando e aromatizando o ambiente. É comum as crianças considerarem a função da planta quase exclusivamente como ornamental, pois suas flores, na maioria das vezes, são vistosas e coloridas (Afonso, 2005). Muitos desenharam flores em vasos enfeitando mesas e janelas. Ao explicar seu desenho, os alunos usaram frases como "Pra enfeitar", "Pra deixar mais bonito o lugar", "Pra poder enfeitar", "Pra deixar o mundo mais perfumado", "Por que é bonita", indicando um conceito muito limitado quanto à relevância das plantas.

15\% dos alunos ressaltaram a importância vegetal para a produção de mel. Para esclarecer seus desenhos, eles usaram as seguintes respostas: "Pra abelha pousar nela e fazer o mel" e "Pra abelha fazer mel". Outro aluno destacou a importância das plantas como fonte de alimento dos animais. Em seu desenho aparece um animal próximo a uma planta. Quando questionado sobre o significado da sua ilustração, ele responde "Pro bicho comer".

No desenho final, os alunos retrataram a importância vegetal de forma mais completa e complexa, integrando os conhecimentos abordados durante a aula. Acreditamos que a aula de campo tenha contribuído para acrescentar novos conhecimentos, pois muitos estudantes ilustraram mais de uma relevância vegetal, demonstrando compreender que os vegetais têm várias importâncias para meio ambiente e para os seres humanos.

Nessa etapa os estudantes expressaram suas concepções sobre a relevância vegetal de diferentes formas: como fonte de alimento para os animais e os seres humanos, habitat de outras plantas e animais, forma de embelezar o meio ambiente, agentes que influenciam no clima e purificam o ar. É importante destacar que todos esses assuntos foram discutidos durante a visita de campo, demonstrando sua efetiva influência na aprendizagem dos alunos.

Ao explicar seus desenhos, respondendo à pergunta "Por que as plantas são importantes?" os alunos usaram as seguintes afirmações: "Pra fazer sombra" "Pra dar sombra, pra dar alimentos e casa pros animais", "Alimento e sombra", "Pros bichos se alimentarem e morarem, pra ter um ar gostoso", "Por causa das frutas para os animais comerem", "Embelezar o ambiente e nascer as frutas".

A figura 6 representa o desenho final do aluno P. Nele o estudante destaca a importância vegetal como habitat de animais - nesse caso, o pica-pau, como o próprio discente explica. Também aborda a importância das plantas em nos fornecer alimentos quando ilustra várias frutas na árvore e informa que as plantas são importantes "pra nos dar alimento". Ainda é possível observar que o aluno retrata as características morfológicas da planta, como as raízes e os galhos com folhas e flores, mesmo sem essa orientação nesse momento, indicando mobilizar os saberes construídos durante a aula de forma menos fragmentada. 


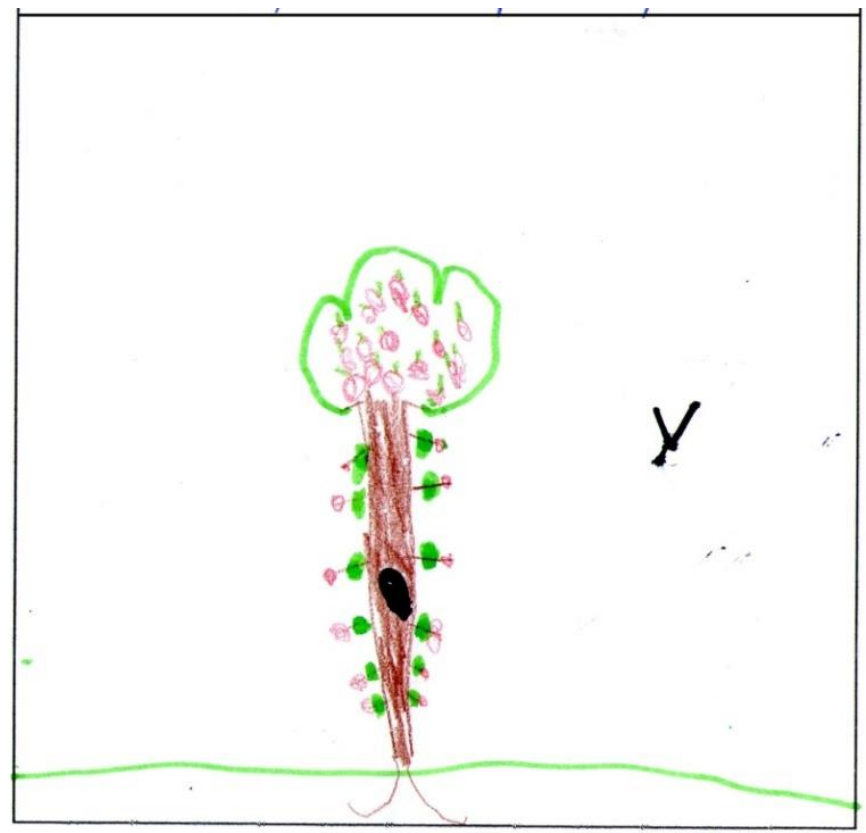

Figura 6 - Desenho final do aluno P.

Para uma melhor análise desses resultados, iremos comparar as produções iniciais e finais de alguns alunos participantes da pesquisa. A figura 7 representa os desenhos do aluno $\mathrm{PE}$.
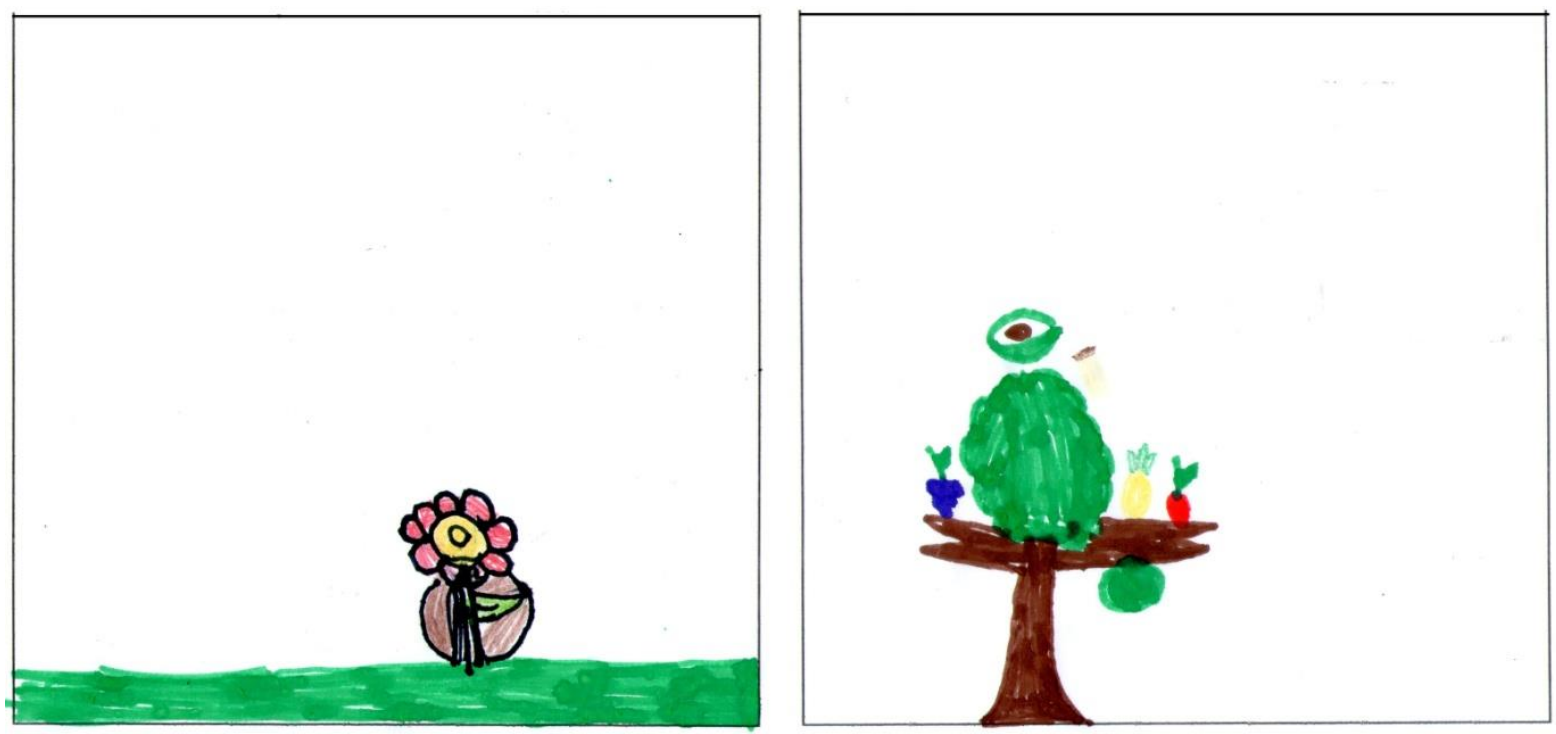

Figura 7 - Desenho inicial e final do aluno PE.

Em sua produção inicial, o aluno desenha uma flor plantada no solo. Para explicar a importância das plantas, PE diz que "elas servem para enfeitar", demonstrando uma concepção restrita sobre o assunto, limitando a relevância vegetal a sua capacidade de tornar os ambientes mais belos e agradáveis.

Em seu desenho final, o aluno retrata a importância das plantas como fonte de alimentos, para os animais e os seres humanos. Ele desenha uma árvore com diferentes frutas, e embora isso seja um equívoco conceitual, já que cada árvore só apresenta um tipo, 
o aluno demonstra ter avançado na compreensão desse saber. Sua explicação sobre o desenho confirma esse progresso, pois PE diz que as plantas são importantes por que produzem "frutas para alimentar a gente e os animais".

A figura 8 reproduz os desenhos da aluna $C$.
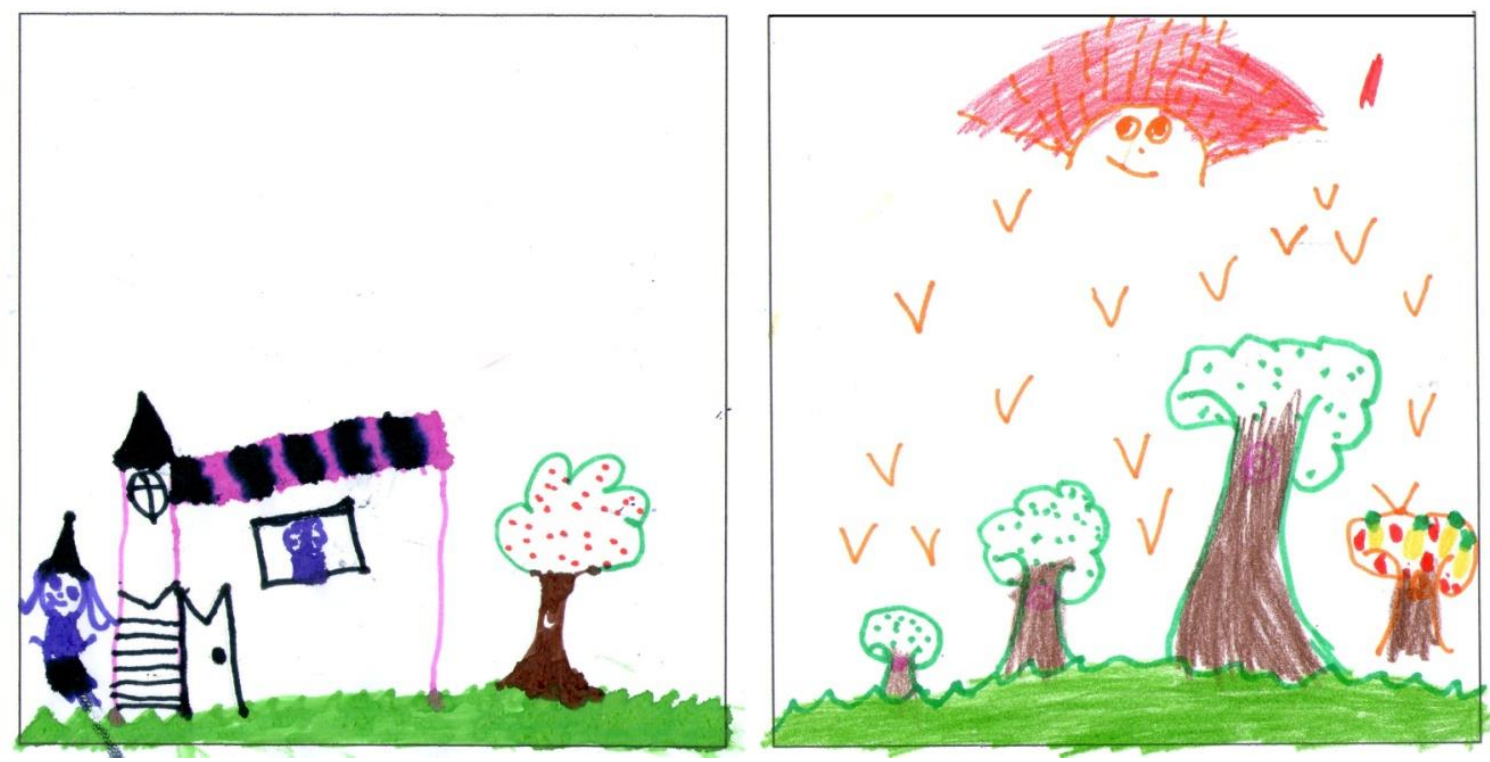

Figura 8 - Desenho inicial e final da aluna C.

Inicialmente a aluna expressa sua ideia sobre a importância vegetal por meio de uma flor plantada em vaso na janela de uma casa. Apesar de também desenhar uma árvore, a explicação da aluna não deixa dúvidas quanto sua intenção, pois ela afirma que as plantas são importantes "pra poder enfeitar", indicando se tratar especialmente da flor. Acreditamos que essa concepção esteja intimamente ligada à rotina familiar. Em muitas casas, as plantas são utilizadas como objetos decorativos. Raven (2007) argumenta que uma das funções vegetais é embelezar o ambiente.

Em seu desenho final, a aluna ainda mantém sua ideia original de que as plantas adornam o ambiente, no entanto, é possível observar que desta vez C retrata um ambiente natural em que aparecem várias árvores, pássaros, o solo e o sol. Consideramos que após a aula em um espaço natural, a aluna verificou essa importância das plantas em relação ao meio ambiente. Destaca-se o tamanho diferente das árvores, característica observada durante a visita ao Parque. Ela também ilustra uma árvore frutífera, destacando a importância vegetal como fonte de alimentos. Ao explicar seu desenho a aluna disse que as plantas são importantes para "Embelezar o ambiente e nascer as frutas". A figura 9 demonstra os desenhos da aluna PA.

Em sua produção inicial, a aluna retrata uma flor no interior do vaso sobre a mesa. Fica claro a intenção de descrever o uso das plantas como meio de tornar as rotinas familiares mais agradáveis. Ao descrever seu desenho, ela diz que as plantas são importantes "para enfeitar".

Em seu desenho final a aluna retrata dois dos conhecimentos discutidos durante a aula de campo: a influência vegetal no clima e a produção de alimentos, nesse caso, as frutas. É possível observar o sol e as nuvens, indicando que PA integrou a árvore ao seu habitat natural. Ela também ilustra um bebê e uma mulher em baixo da árvore, desfrutando de sua 
sombra. Essa concepção se torna importante já que ao perceber a relevância vegetal associada ao bem-estar humano, a aluna poderá estabelecer uma postura de conservação do meio ambiente e não de mera expectadora ou de usuária de seus recursos (MELLO E TRAJBER, 2007).
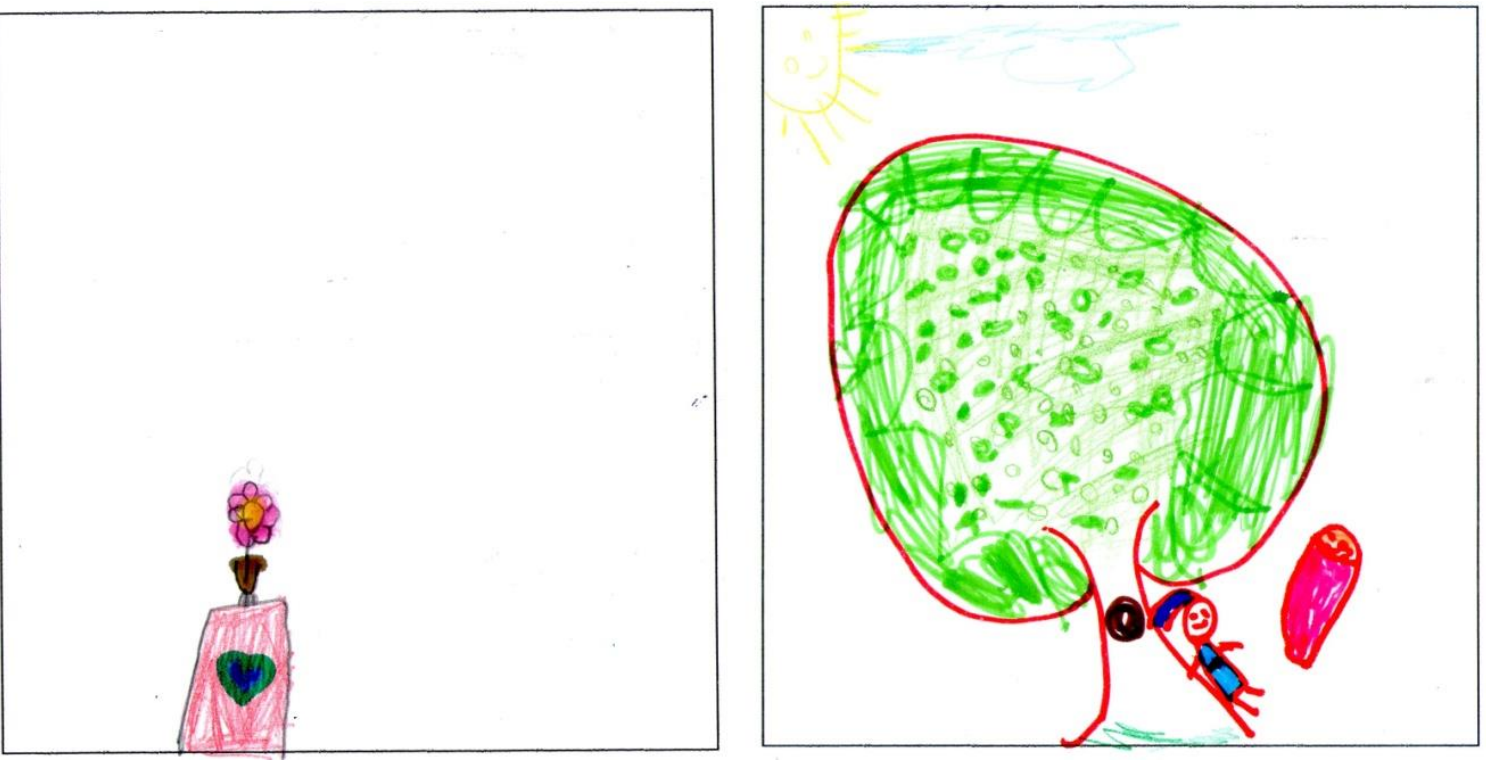

Figura 9 - Desenho inicial e final da aluna PA.

\section{Considerações finais}

A proposta deste trabalho foi discutir o quanto e como as aulas de campo podem colaborar para o ensino e aprendizagem de ciências, especificamente em turmas dos anos iniciais do Ensino Fundamental.

Considerando os resultados apresentados, as aulas de campo parecem contribuir para a construção de conhecimentos científicos nessas séries, visto que possibilitam a aprendizagem de conteúdos bem como a formação crítico-social do estudante, como orientam os PCN's quanto ao ensino de ciências (BRASIL, 1997).

Mais que isto, essa metodologia permite um ensino menos fragmentado, em que o aluno pode aprender a partir da observação direta, da manipulação, da formulação de hipóteses e da investigação. Contribui também no sentido de tornar a aprendizagem menos abstrata, já que os alunos têm um suporte de informações vindo da realidade concreta.

Destaca-se também a motivação promovida pelas aulas de campo. Seniciato et al (2006) afirma que ao realizar aulas em outros espaços que não o escolar, cria-se uma atmosfera de alegria, criatividade e encorajamento, que envolve e estimula os alunos a aprender. Os autores ainda argumentam que as aulas teóricas não são suficientes para estabelecer referências positivas em relação aos ambientes naturais. Desse modo, é necessário que os estudantes tenham essa vivência para desenvolver uma postura crítica, de conservação ambiental.

Na avaliação das imagens, percebeu-se um importante acréscimo de informações após a aula de campo. Os desenhos finais, que antes estavam limitados, em sua grande maioria, às experiências domiciliares, comunicaram a perspectiva do aluno de forma mais completa e 
complexa, abordando os vegetais em seu habitat natural e demonstrando os conceitos construídos durante a aula.

Acreditamos que os espaços não formais de educação possibilitam experiências importantes no processo de aprendizagem que dificilmente seriam recriadas nos ambientes formais. No entanto, nossa intenção não é afirmar que estes sejam menos importantes que aqueles, e sim destacar que as aulas em espaços não formais apresentam qualidades que o espaço formal não possui.

Os resultados encontrados nessa pesquisa sugerem que os alunos construíram conhecimentos científicos sobre as plantas, sua importância para o homem e para o meio ambiente a partir da aula de campo desenvolvida em fragmentos do ecossistema terrestre Mata Atlântica.

\section{Referências}

AFONSO, M. A Flor:O Ciclo de Vida. Ciência Viva - Agência Nacional para a Cultura Científica e Tecnológica. Lisboa: Ciência Viva, 2005.

AMABIS, J. M.; MARTHO, G. R. Biologia 2: Biologia dos organismos. $4^{a}$ ed. São Paulo: Moderna, 2015.

BRASIL. Ministério da Educação. Secretaria de Educação Fundamental. Parâmetros Curriculares Nacionais: ciências naturais ( $1^{\circ}$ e $2^{\circ}$ ciclos do ensino fundamental). Brasília: MEC, 1997.

BRASIL. Ministério da Educação. Secretaria de Educação Fundamental. Parâmetros Curriculares Nacionais: meio ambiente, saúde. Brasília: MEC, 1997.

CURTIN, C. Eliciting Children's Voices in Qualitative Research. American Journal of Occupational Therapy, v.55, p.295-302.2000.

FILHO, A. B.S.; SANTANA, J. R. S.; CAMPOS, T. D. O ensino de ciências naturais nas séries/ anos iniciais do ensino fundamental. In: $\vee$ Colóquio Internacional "Educação e Contemporaneidade", São Cristovão (SE), p.1-9, 2011.

GOHN, M. G. Educação não formal e o educador social: atuação no desenvolvimento de projetos sociais. $1^{a}$ ed. São Paulo, Cortez, 2010. (Coleções questões da nossa época, v.1).

KRASILCHIK, M. Prática de Ensino de Biologia. $4^{a}$ ed. rev. e ampl., $3^{a}$ reimpr. São Paulo: Editora da Universidade de São Paulo, 2011.

LIMA, M. E. C. C.; MAUÉS, E. Uma releitura do papel da professora das séries iniciais no desenvolvimento e aprendizagem de ciências das crianças. Ensaio Pesquisa em Educação em Ciências. Belo Horizonte, v.8, n.2, p.161-175, 2006.

LORENZI, H.; SOUZA, H. M. Plantas ornamentais no Brasil: arbustivas, herbáceas e trepadeiras. 4ª ed. São Paulo: Nova Odessa, Instituto Plantarum, 2008.

MARANDINO, M.; SELLE, S. E.; FERRERA, M. S. Ensino de Biologia: histórias e práticas em diferentes espaços educativos. $1^{a}$ ed. São Paulo: Cortez, 2009. (Coleção Docência em Formação. Série Ensino Médio). 
MELLO, S. S.; TRAJBER, R. (Coords). Vamos cuidar do Brasil: conceitos e práticas em educação ambiental na escola. Ministério da Educação, Coordenação Geral de Educação Ambiental: Ministério do Meio Ambiente, Departamento de Educação Ambiental. Brasília: UNESCO, 2007.

PAVÃO, A. C. (Coord.). Ministério da Educação. Secretaria de Educação Básica. Ciências: ensino fundamental. v.18. Brasília: MEC, 2010. (Coleção Explorando o Ensino).

PUNCH, S. Research with children: the same or different from research with adults?. Childhood. Londres, v.9, n.3, p.321-341, 2002.

RAVEN, P. H. Biologia Vegetal. Rio de Janeiro: Guanabara Koogan, 2007.

SENICIATO, T.; CAVASSAN, O. Afetividade, motivação e construção de conhecimento científico nas aulas desenvolvidas em ambientes naturais. Ciência \& Cognição. Rio de Janeiro, v.13, n.3, p.120-136, 2008.

SENICIATO, T.; CAVASSAN, O. Aulas de campo em ambientes naturais e aprendizagem em ciências - um estudo com alunos do ensino fundamental. Ciência \& Educação. Bauru, v.10, n.1, p.133-147, 2004

SENICIATO, T.; CAVASSAN, O. Construindo valores estéticos nas aulas de ciências desenvolvidas em ambientes naturais. Ensaio. Rio de Janeiro, v. 8, n.2, p. 97-109, 2006.

VIEIRA, V.; BIANCONI, M. L.; DIAS, M. Espaços não-formais de ensino e o currículo de ciências. Ciência e Cultura, v. 57, n. 4, p. 21-23, 2005.

VIVEIRO, A. A.; DINIZ, R. E. da S. As atividades de campo no ensino de ciências: reflexões a partir das perspectivas de um grupo de professores. In: NARDI, R (org). Ensino de ciências e matemática, I: temas sobre a formação de professores. São Paulo: UNESP, 2009. 